\title{
Letramento, novas tecnologias e a Teoria Ator-Rede: um convite à pesquisa ${ }^{1}$ \\ Marcelo El Khouri Buqato
}

A busca de um sentido político para as chamadas "novas tecnologias" da informação e da comunicação - as quais, por sinal, não são mais exatamente novas, nem podem plausivelmente ter seu significado restringido por funções delimitadoras tais como informar e comunicar - é possivelmente uma das tarefas mais urgentes para as Ciências Humanas nesse início de século, em particular no contexto brasileiro. Isto porque a idéia de modernização, tão intimamente conectada (metonimicamente) aos artefatos e (metaforicamente) aos modos de fazer ditos digitais, modos que reconfigurariam, supostamente, todos os campos da prática social no país, choca-se aqui com uma modernidade que ainda não chegou a se instalar - i.e. uma "pré-modernidade" que confia, ainda, nas promessas de um welfare state que, em outros lugares, já está sendo desmontado.

Essa idéia é, portanto, recebida com o contra-fogo dos antimodernos e com o ceticismo dos pós-modernos, todos eles de certa forma já "incluídos" nessas reconfigurações, portadores de smartcards que lhes facultam deslocarem-se, alimentarem-se, baterem o ponto ou receberem um salário-social; são todos garçons, limpadores ou comensais de uma mesma mesa de bar em que já podem receber um SMS da família para desconfirmar sequestros imaginários, fabulados dentro de uma cela de cadeia, a mil quilômetros dali.

Assim como se imiscuem na vida social e saturam as práticas de novos significados ideológicos, as ditas novas tecnologias também estão submetidas a dois conjuntos de práticas que, para Bruno Latour, constituem exatamente o que é designado pela palavra "moderno": as de purificação e as de tradução. As práticas de purificação criam zonas ontológicas claramente distintas entre humanos (sociedade) e não-humanos (natureza), e assim permitem situar as máquinas (sobretudo os computadores) numa epistemologia do extra-humano (extra-social, extracultural). São práticas que cortam os finos fios das tramas de ciência, política, economia, direito, religião, técnica e ficção que engendram nossas máquinas onipresentes, e os separam em tantos segmentos quanto forem as disciplinas puras que as tomem como objeto a ser desvendado. Já as práticas de tradução, possibilitadas, justamente, pelas de purificação, as quais criam repositórios de fatos aparentemente objetivos e distintos, fazem proliferar híbridos de natureza e cultura ${ }^{2}$, misturas complexas que apenas uma topologia de redes pode capturar, em contraste com a topologia de superfícies/áreas adotada pelas práticas de purificação.

A ligação entre esses dois tipos de prática estaria no cerne do que o autor chama de "a constituição moderna”. Ser moderno é, em essência, acreditar nessa separação de propriedades, poderes e maneiras dos humanos e dos não-humanos de se agruparem e de se governarem e, ao mesmo tempo, presenciar a proliferação dos hỉbridos. 
A proposta de Latour e colegas para o estudo dos significados teóricos e políticos das tecnologias, conhecida como Teoria Ator-Rede (doravante TAR), funda-se no exame etnográfico das redes de práticas sociais interdependentes (e dos objetos que estabelecem essas interdependências) no campo da tecnociência, um exame que obedece ao princípio metateórico da simetria generalizada, isto é, o pressuposto de que humanos e não-humanos são actantes (no sentido greimasiano de participantes semióticos da narrativa) definíveis relacionalmente, a partir das maneiras como agem/resistem nessas redes de práticas. Isto permite aos que utilizam a teoria não apenas evitar a crença positivista nas tecnologias como atores autônomos, dotados de algum tipo de força transcendente encarnada em sua eficiência técnica, como também integrar, por força da topologia de redes, processos acionais em diferentes escalas (local e global), por meio de objetos semióticos descritos como fronteiriços ou boundary objetcs, termo emprestado da Teoria Ator-Rede à sociologia da Ciência e Tecnologia de orientação sociointeracionista (STAR; GRIESEMER, 1989).

É a partir dessa perspectiva que me proponho, neste trabalho, a refletir sobre um dos híbridos de que se ocupam no momento diversos pesquisadores da linguagem no campo aplicado: o assim chamado "letramento digital". Mais especificamente, o que se segue é um convite à pesquisa em torno de uma concepção de letramento (digital) que o reconheça como uma rede heterogênea, isto é, uma rede feita de circulações e não de "laços" ou "atributos", na qual humanos e não-humanos negociam interesses e interpretações do que consideram ser seus problemas e os problemas dos outros. Esse convite, diga-se de passagem, não é exatamente meu, embora eu o tenha formulado anteriormente, de forma bastante mais insipiente (BUZATO, 2009); sou apenas mais um alistado numa translação que vem de outros lugares (LEANDER, 2006; IADEMA, 2003; CLARKE, 2001 e HAMILTON, 2001, por exemplo).

Não se trata de uma pesquisa simples de se justificar, falando do lugar de onde falo, porque ela não se volta para maneiras de purificar, estandardizar, ou criar metrologias para o letramento digital de modo a equacionar "problemas sociais", como se esperaria, em princípio, de uma pesquisa no campo aplicado. Ao contrário, trata-se de rastrear os vínculos que constituem letramento digital como um(a) ator-rede, resgatando, assim, a vivacidade de incertezas (e controvérsias) sobre o que é letramento, o que é tecnologia e o que é sociedade (e, portanto, sobre o que são os "problemas sociais" que se quer resolver). Para tanto, parto, de uma visão performativa do social, contraposta à visão "ostensiva" que norteia boa parte dos estudos nesse campo i.e. uma visão comprometida com um social existente "lá fora", antes da ação e dos atores. Uma visão performativa do social nos diz que a sociedade é construída por meio dos muitos esforços e resistências dos atores humanos e não-humanos que dela participam para defini-la e estabilizá-la (STRUM; LATOUR, 1987). Trata-se de pensar no que Bruno Latour chama de uma "sociologia das associações" (em lugar de uma sociologia "do social"), ou seja, pensar em um social entendido como um punhado de vínculos entre atores humanos e não humanos em processos de translação (LATOUR, 2005).

Se quiser fazer essa pesquisa a partir da Teoria Ator-Rede, não poderei iniciá-la de outra forma que não seguindo sua primeira regra metodológica: "estudamos ciência em ação, e não a ciência ou a tecnologia pronta; para isso, ou chegamos antes que fatos e 
máquinas se tenham transformado em caixas-pretas, ou acompanhamos as controvérsias que as reabrem" (LATOUR, 2000, p. 412). Partindo desse postulado, destaco, inicialmente, a controvérsia sobre as relações entre tecnologia e sociedade (entendida ostensivamente) subjacente às diversas concepções de letramento (digital) em circulação e em disputa no campo aplicado dos estudos da linguagem nesse momento. Em seguida, proponho uma visada sobre o próprio conceito de letramento, e sobre a maneira como o fenômeno tem sido estudado, baseada nos pressupostos da Teoria Ator-Rede. Finalizo minha reflexão explorando alguns conceitos dessa teoria que me parecem particularmente úteis para os que se debruçam sobre o problema da relação entre prática, contexto e subjetividade, no âmbito dos estudos do letramento, tendo como foco as assim chamadas novas tecnologias.

São basicamente duas as grandes correntes, ou tipos de discursos, incidentes sobre a relação tecnologia-sociedade, que têm influenciado a pesquisa em letramento digital e inclusão digital: determinismo e neutralismo (WARSCHAUER, 2003). Os discursos deterministas tomam por pressuposto que o desenvolvimento de uma (nova) tecnologia se dá por caminhos que estão além do controle dos homens, e, por conseguinte, que a tecnologia é capaz de exercer, de formas autônomas, inerentes à sua própria eficácia técnica, "impactos" sobre o "mundo social", visto como sendo externo a ela. Como "causas", i.e forças autodeterminadas ou exógenas, tecnologias como a escrita seriam capazes de formatar grandes mudanças nas estruturas e processos macrosociais, bem como nas capacidades cognitivas individuais dos seres humanos, causando brechas (divides) entre grupos sociais ao longo do tempo e do espaço. Entre essas brechas estaria a notória "brecha digital" (digital divide), cuja superação tem sido alvo de massivos investimentos intelectuais e financeiros em todo o mundo há pelo menos duas décadas.

Quando pensamos em tecnologias das letras, a controvérsia remete diretamente ao corpo de pesquisas realizadas a partir de meados do século XX em torno da noção de "brecha do letramento" (GOODY; WATT, 1963; GOODY, 1986; OLSON, 1977). O argumento principal desses trabalhos, como é sabido, se baseia numa relação supostamente causal e unilateral entre o surgimento (suposto) da escrita alfabética na antiguidade clássica e o desenvolvimento da capacidade de pensamento abstrato nos indivíduos e sociedades ocidentais ditas modernas. A refutar esse argumento está, ainda hoje, o clássico trabalho de Sylvia Scribner e Michael Cole com o povo Vai, na Libéria (SCRIBNER; COLE, 1981). Aproveitando um contexto de pesquisa especialmente propício, em que diferentes tipos de escrita, em diferentes línguas, eram utilizados em práticas sociais diferenciadas, os autores demonstram, por meio de testes psicolinguísticos e psicológicos diversos, que é virtualmente impossível isolar, na gênese das habilidades cognitivas ligadas ao uso da escrita, sua "natureza tecnológica" da sua "natureza social", ou seja, dos contextos e práticas socioculturais específicas, que engendram finalidades e funções específicas para a escrita. Assim, em lugar de "força autônoma", os autores nos levam a pensar na escrita como um "ator" enredado em processos tais como escolarização e urbanização.

Em termos da teoria Ator-Rede, o que se pode atacar nos discursos deterministas, para além do seu reducionismo, é a própria noção de causalidade que os fundamenta. À noção de causalidade, entendida como "um segundo termo totalmente previsto pela existência do primeiro” (LATOUR, 2005, p. 58), a TAR opõe as de deslocamento, desvio 
e/ ou desarticulação, ao postular a existência de dois tipos de actantes em qualquer assemblage dita social: intermediários e mediadores. Redizendo o que dizem os críticos do determinismo tecnológico nos termos da TAR, o problema com a hipótese da brecha é que seus autores tratam como intermediários o que seriam mediadores: a escrita, a letra, o texto, o livro, e o(s) letramento(s).

Um intermediário, na TAR, é um actante cujos outputs estão perfeitamente previstos pelos inputs que recebe; em outras palavras, um intermediário simplesmente transporta uma causa anterior, sem nada a ela acrescentar. Assim, para os autores da brecha, a racionalidade (expressa em termos de capacidades silogísticas e de "raciocínio abstrato") do ocidente, a organização democrática da sociedade, a possibilidade do pensamento metalinguístico, entre outras, são causas (de desenvolvimento social e cognitivo) que a escrita, dada sua suposta capacidade de veicular "informação sem deformação", teria transportado desde a antiguidade clássica até os mais diversos contextos socioculturais e espaciotemporais.

Mediadores, por outro lado, não transportam sem deformação, e de seus efeitos não se podem deduzir causas. Eles simplesmente oferecem ocasiões, circunstâncias e precedentes; são actantes que, quando acionados como veículos, fazem outras coisas que não as esperadas. Vista como mediador, a escrita alfabética não separa o sentido da fala do sentido do falante, como queriam os autores da hipótese da brecha; ao contrário, ela adiciona mais e mais sentidos, alista e põe a negociarem interesses e contornarem resistências entre si toda uma gama de outros atores, humanos $e$ não-humanos. Entre os humanos, poderíamos listar os tipógrafos, os livreiros, os editores, os burocratas de estados-nações emergentes, os "autores" e leitores, entre outros. Entre os não-humanos, podemos pensar nos materiais de suporte que aceitavam ou se recusavam a ser prensados, costurados, encadernados, empilhados e transportados, em tipos gráficos cujos traços visuais distintivos não resistiam nem além e nem aquém do compatível com a maleabilidade do chumbo, em organizações textuais que aceitavam espaços em branco entre e ao redor de parágrafos, de modo que se pudesse usar pinos ou parafusos para fixar o papel aos mecanismos de prensagem, em densidades e tamanhos de folhas de papel que, quando amarradas juntas, pesassem exatamente o suficiente para que as pessoas pudessem carregá-las consigo para onde fossem, ou recebê-las, via algum tipo de transporte terrestre ou marítimo, onde estivessem, e assim por diante.

Cada um desses mediadores, por sua vez, pôde ser alistado por e/ou alistar outros atores em outras redes. Foram, assim, se configurando certos efeitos de rede que não poderiam ser deduzidos diretamente de uma causa anterior e exterior a essa concatenação. A normalização da escrita e os esquemas de reprodutibilidade técnica são alistados na construção de um mercado das letras e, então, de uma massa de leitores. A pontuação unívoca, que permitiu ao leitor recitar o texto para si mesmo em silêncio, transportou a leitura e a escrita para o foro privado, como ato individual (CHARTIER, 1999). Nesse foro, a escrita prestou-se a registrar e acumular pensamentos ou prazeres proibidos, individuais. Ao ser estabilizada, ela permitia estabilizar, por assim dizer, uma nova moralidade e uma nova subjetividade (MAINGENEAU, 1995). Quem controla o que resulta dessa leitura e escrita, nessas interações locais que a imprensa ajudou a pré-formatar? Que racionalidades, moralidades, subjetividades constituem o "social" que esses atores 
humanos e não-humanos renegociam constantemente, enquanto se concatenam, e que não existe "lá fora" dessas circulações? Essas são perguntas que os deterministas não podem responder.

Supostamente opostos ${ }^{3}$ aos discursos deterministas estão os discursos neutralistas ou instrumentais da tecnologia (WARSCHAUER, 2003), que respondem àquelas perguntas de maneira peremptória: nós, os que construímos e utilizamos as tecnologias, controlamos esses efeitos, porque as engenhamos e as utilizamos de acordo com nossas próprias índoles, desejos ou intenções; as controlamos porque somos "humanos", dotados de livre-arbítrio, enquanto elas são "não-humanas", incapazes de agir por si próprias; porque somos "sujeitos", sendo elas meros "objetos". Tecnologias são para os neutralistas, em outras palavras, fiéis intermediários de subjetividades e/ou individualidades que pré-existem a elas (o sujeito privado, dotado de desejos e curiosidades proibidas ou permitidas, virtuosas ou desviadas, usa o livro impresso, e não vice-versa).

Central tanto para os discursos neutralistas (embora importante também para os deterministas) é o conceito de affordance $e^{4}$ i.e., a qualidade intrínseca e pré-dada de um objeto ou um ambiente que, quando percebida, permite que o indivíduo o utilize para realizar um certo tipo de ação. Tal qual maçãs do paraíso, as affordances são "dádivas" que devemos saber utilizar, ou das quais devemos nos abster, de modo a nos constituirmos como seres éticos, é o que pensam os neutralistas. Frequentemente citado nesses discursos é o exemplo de uma faca, cujas affordances permitem cozinhar, curar ou matar. O manejo "socialmente responsável" e "moralmente correto" das affordances do aço é a chave do controle social sobre os seus efeitos. E, caso alguém utilize essas affordances em ações socialmente destrutivas ou moralmente inaceitáveis, sempre se pode usá-las também contra esses indivíduos, colocando-os, por exemplo, atrás de grades feitas de aço, cortando-lhes o pescoço com guilhotinas de aço, ou usando bisturis de aço para lobotomizá-los!

Do ponto de vista da TAR, o primeiro problema com os discursos neutralistas é que todo instrumento, por mais simples que seja, transforma-se e especializa-se em seu próprio design e em seu significado (enquanto instrumento), na medida em que vai criando vínculos com outros mediadores. Ao especializar-se, isto é, vincular-se com outros atores em outras ações, todo instrumento não só se transforma, como transforma a natureza da tarefa a que se presta. Não há, em outras palavras, neutralidade, a menos que também não haja ação. Uma faca, um bisturi e uma navalha, por exemplo, compartilham a possibilidade de ação "cortar tecido biológico"; mas essa affordance não pode ser entendida fora da relação entre o que corta (açougueiro, barbeiro, cirurgião) e o que é cortado (filé, barba, miocárdio). Esse vínculo, entre o que corta e o que é cortado, muda completamente o conjunto de affordances relevantes (cortar fácil, cortar macio, cortar preciso e sem dor), define conjuntos diferentes de aliados (munhequeira, espuma, marcador cirúrgico) e transforma completamente os papeis actanciais do envolvidos (o sangue, o peso do metal, ou as bactérias, por exemplo, são oponentes ou adjuvantes, conforme o caso).

Uma vez transformadas/especializadas nessas translações, as tecnologias ganham inércia própria, isto é, resistem a novos deslocamentos e refratam certas agentividades em favor de outras. Pode-se cortar bifes com um bisturi ou fazer uma cirurgia com uma navalha, em último caso, mas a mão do açougueiro e a mão do médico não serão as 
mesmas: passarão de intermediários a mediadores; o que farão não se poderá mais prever, a menos que se recrute mais e mais atores adicionais para estabilizá-las (um diploma, um conselho de ética, uma luva feita de malhas metálicas, etc). Cada um desses, porém, trará consigo mais um conjunto de incertezas: as diferenças entre açougueiro e cirurgião, filé e miocárdio, matar e curar voltam a estar em disputa. A polêmica está reaberta. A tecnologia já não é mais neutra.

A história das TIC está repleta de exemplos ilustrativos de vinculações entre mediadores travestidos em intermediários, aparentemente neutros: a utilização do alfabeto latino tal qual utilizado no inglês escrito como base dos primeiros sistemas de codificação dos computadores, a opção de emular nos teclados de computador a mesma disposição QWERTY das antigas máquinas de escrever e, mais recentemente, a introdução da metáfora da mesa de trabalho de escritório (desketop) nas interfaces gráficas dos computadores pessoais, são alguns deles. Trata-se de escolhas que atendem às necessidades e hábitos cognitivos de pessoas já familiarizadas com o alfabeto latino, com o idioma inglês, com a técnica da datilografia, e com as disposições habituais para a manipulação, produção, armazenamento e recuperação de documentos utilizados em escritórios.

Ao mesmo tempo em que permitem ao letrado (digital) agir por meio de seu computador, essas escolhas alteram a natureza da ação letrada, i.e elas fazem o letrado agir de certa forma, constituem formas de veicular, com mais ou menos deformações, agentividades não-locais as quais reabrem o vínculo entre letrado e letra, letra e lugar, lugar e trabalho e assim por diante.

Só muito recentemente as pesquisas sobre letramento começaram a dar atenção a esse postulado central da TAR: "a ação é emprestada, distribuída, sugerida, influenciada, dominada, traída, traduzida” (LATOUR, 2005, p. 46). Por muitos anos já temos insistido na capacidade do local de refratar, transformar, vernacularizar, etc, o letramento (entidade global), em termos de letramentos "situados", incrustados em práticas quotidianas, valores, atitudes, e esquemas cognitivos locais ${ }^{5}$. Isso se deve, em parte, a uma certa negligência com os componentes materiais/tecnológicos desses letramentos, em favor dos seus componentes simbólicos, discursivos, ideológicos, etc. vistos, aparentemente, como ostensivamente sociais. Mas mesmo quando a introdução/intromissão das novas tecnologias nesses eventos locais de letramento nos forçaram a não mais negligenciar o componente tecnológico, as atenções se voltaram, em boa parte dos casos, para as diferenças entre a página impressa e a tela eletrônica, enquanto "suportes", e para as estruturas textuais que esses induzem, isto é, as atenções parecem ter se voltado para a tecnologia pensada ostensivamente. Ao que parece "estivemos sofrendo de uma certa miopia", ao "focalizar o que os textos significam em lugar de focalizar o que eles fazem" (LEANDER; LOVVONR, 2006, p. 292).

Ao tentar entender letramentos "em contextos" para combater a hipótese da brecha, parece que nos apoiamos em dois pressupostos que a TAR nos leva a contestar frontalmente. O primeiro é o de que o contexto (de um letramento) funcionaria como um contêiner pré-existente à própria prática letrada (isto é, um contexto ostensivo, "lá fora", tal como o postulado pela "sociologia do social"). O segundo, o de que seria possível isolar as ações que tentávamos interpretar em dois compartimentos isolados, o global e o local ${ }^{6}$. 
Para a TAR, o primeiro pressuposto é inválido porque "movimento e deslocamento (desvio, desarticulação) vêm primeiro, lugares e formas, depois" · Já o segundo não se sustenta porque "global e local são sítios que não existem", "utopias encantadas", impossíveis de localizar no mapa: "nenhum lugar é suficientemente dominante para ser global, nem suficientemente autocontido para ser local” (LATOUR, 2005, p. 204). Isso posto, as interações locais (eventos de letramento, se assim as quisermos chamar) que estivemos estudando tão cuidadosamente para refutar a teses deterministas e a hipótese da brecha, não são, nunca foram, outra coisa que não efeitos de circulações. É isso, em última instância, que deveria ter-nos chamado à atenção quando da intromissão das novas tecnologias no que tínhamos concordado em conceituar como letramentos: elas nos permitem tornar visível/rastreável aquilo que estava presente, antes (e não agora, "dentro delas"), apenas "virtualmente".

A TAR fornece cinco princípios/pressupostos que nos permitem repensar a maneira como temos estudado as interações locais (face-a-face) em torno de textos. São princípios que, com muito menos dificuldade, temos adotado para estudar interações ditas "virtuais", porque mediadas por computador, ou realizadas a distância. Destaco aqui dois desses princípios (LATOUR, 2005, p. 200) ${ }^{7}$, diametralmente opostos aos dois, já citados, que tradicionalmente tem norteado os estudos do letramento. Inspirado em um exemplo do próprio autor ${ }^{8}$, vou ilustrá-los com uma situação bastante corriqueira nos estudos de letramento: professora e alunos discutindo um texto impresso em sala de aula.

O primeiro princípio diz que nenhuma interação é isotópica, isto é, que aquilo que está agindo num mesmo momento, em qualquer lugar, vem de muitos outros lugares, de muitos materiais e atores distantes. No nosso exemplo, esses atores podem tomar a figura do autor do livro didático, dos parâmetros curriculares que o nortearam na escolha do texto inserido no livro, do escritório que desenhou a sala e o mobiliário, do funcionário que organizou a distribuição dos alunos em turmas, de acordo com um certo critério, do engenheiro que calculou a quantidade de eletricidade necessária para iluminar o ambiente, do fabricante de cadernos cujas decisões afetam desde a quantidade de notas que se pode tomar até o tipo de aviãozinho ou de bilhetinho que se pode fazer, entre outros. Cada um desses sítios/atores distantes, para a TAR, dá forma, de alguma maneira, àquela sala de aula, e ao que acontece ali, i.e. cada um age, por diferentes meios e materiais que transportam sua agentividade, de modo a tornar aquilo uma interação local. Não o fizeram, obviamente, para essa ocasião em especial. Mas sem a quantidade massiva de templates (modelos, padrões, metrologias, etc.) despejados sobre aquele local, como professores e alunos poderiam das significado ao que ali acontece, e, portanto, ao texto que ali discutem?

O segundo princípio que destaco diz que interações não são homogêneas. Para além da professora e dos alunos, há ali uma multidão de outros participantes "não-humanos, não-subjetivos e não-locais" (LATOUR, 2005, p. 201) que se reúnem para que a ação aconteça, ou melhor, que transportam a ação para aquele lugar e dela para outros, por meio de infinitos canais e "passagens de bastão". Antes que os impulsos nervosos levem as letras do papel ao cérebro da professora e de seus alunos, e daí o significado do que lêem às suas bocas, as marcas tipográficas foram trazidas ao papel por uma impressora, e a ela de um lap top, por um 
conjunto de impulsos elétricos, e a esse, via sinais analógicos de um teclado, pelos dedos do autor, e a esses, via sistema nervoso, de outros textos que leu, e assim por diante.

Se quiséssemos/pudéssemos seguir toda essa cadeia de atores humanos e não-humanos para além ou para aquém da interação local (a aula), a quantidade de participantes diferentes rapidamente tenderia ao infinito. Se pudéssemos rastrear cada um dos vínculos que constituem cada um desses atores-rede, seja por curiosidade, ou porque eles mesmos nos tivessem levado a isso, ao deixarem de cumprir seu papel de intermediários fiéis ${ }^{9}$, rapidamente a contagem desses vínculos e revezamentos tenderia ao infinito. Seguindo essa cadeia retrospectivamente, descobriríamos, por exemplo, que um lap top utiliza, em seus componentes, um material raro chamado Coltano (ou columbita-tantalita), cuja extração, nas minas no Congo, envolve a exploração do trabalho infantil, o desalojamento de comunidades tradicionais e o financiamento de guerrilhas (VIEIRA, 2009). Seguindo aquele mesmo evento local prospectivamente, isto é, seguindo cada um desses alunos, esse professor, seus textos, suas próximas interações face-a-face, ou mediadas pelo computador, a que e a quantos outros atores-rede (e/ou letramentos) chegaríamos, com quais consequências para cada um deles enquanto "sujeito"?

Quando assumimos, portanto, que as interações, mediadas por computador ou não, são heterotópicas e heterogêneas, atingimos em cheio um outro pilar do edifício "letramento": a noção de que os atores humanos são "sujeitos" ou "indivíduos" dotados de algum tipo de equipamento intelectual "lá dentro" que, por vezes, chamamos de "competência". Sem esse "equipamento", "os atores humanos permaneceriam, mesmo que envolvidos pelo arcabouço mais bem engenhado, incapazes de interpretar o que está dado; eles permaneceriam tão desconectados do significado daquele sítio quanto um gato perambulando pela Acrópole" (LATOUR, 2005, p. 206).

Nos estudos de letramento até aqui, esse “equipamento interior" é, a exemplo do que fazemos com a idéia de contexto, muitas vezes tratado por meio de uma dicotomia. Ou os sujeitos são livres, criativos, capazes de reconverter (ou subverter), vernacularizar (ou localizar) os símbolos, as máquinas e os significados dos eventos a partir do seu “interior", ou são completamente assujeitados à estrutura, às restrições externas (da língua, da tecnologia, da instituição, etc.), ao habitus ou a quaisquer outras forças que os levam a agir (ou não agir), pensar (ou não pensar), dizer (ou não dizer). Há, por certo, tentativas de conciliar as vontades do sujeito e da estrutura nas teorias de letramento, orientadas, sobretudo, por algum tipo de compromisso moral e/ou político com o "essencialmente humano"; mas mesmo essas teorias, na maioria das vezes, não conseguem escapar da armadilha do social ostensivo, "lá fora", e do subjetivo inacessível, "lá dentro".

A TAR tenta requalificar a discussão em torno da relação indivíduo-estrutura desconsiderando, justamente, a ideia de "dentro e fora". Dessa forma, também ajuda a requalificar a pergunta sobre a relação entre eventos e práticas, e/ou sujeitos e contextos, nos estudos de letramento. Não se trata mais de saber como essa prática produz essa subjetividade acessível nesse evento, nem de como esse individuo subverte esse processo de subjetivação de modo a emancipar-se nessa instituição. Trata-se de perguntar de onde vem, e quais são os "veículos que transportam individualidade, subjetividade, pessoalidade, e interioridade" (LATOUR, 2005, p. 207; ênfases adicionadas). 
$\mathrm{Na}$ TAR, os eventos locais (de letramento, inclusive), como já dito, são pré-formatados por templates ou localizadores que "contextualizam" a ação. Mas esses templates ou localizadores projetam apenas um sujeito/indivíduo "genérico". Isso podemos perceber, facilmente, toda vez que sentamos em uma poltrona de avião, comemos uma pizza, ou lemos um manual de montagem de alguma máquina que compramos: são coisas projetadas para "alguém como eu", mas não projetadas "para mim". Há, portanto, um gap, uma lacuna a ser preenchida "entre os atores genéricos, pré-formatados por esses movimentos e o curso da ação realizada por participantes totalmente individualizados" (LATOUR, 2005, p. 205). Dito de outra forma, para que essa ação projetada se transforme em ação executada (e portanto, efetivamente circulada) é necessário que os atores estejam equipados com uma certa "competência"10.

Nas visadas tradicionais do letramento (enquanto tecnologia ou enquanto prática social, não importa), essa competência só pode provir de duas fontes: ou se nasce com ela, quando se nasce "humano", ou se é moldado nela, por força da "estrutura social". Em lugar de recursos locais/interiores, ou institucionais/exteriores, a TAR nos faz pensar nessa competência como um conjunto de subjetificadores, individualizadores ou persolanizadores que vamos acumulando enquanto atores-rede, ou ainda, aproveitando a metáfora criada pelos programadores da Web, num conjunto de plug-ins. O que há, portanto, não é uma subjetividade no interior do sujeito, ou uma subjetivação produzida exteriormente a ele: há plug-ins que circulam incessantemente, os quais podemos "baixar" de modo a nos tornarmos, localmente e provisoriamente, competentes (LATOUR, 2005, p.204).

É importante, embora difícil, não confundir essa proposição da TAR com algumas formas de descrição do sujeito dito pós-moderno. Não se trata de dizer que o sujeito é, a partir de algum ponto na história do capitalismo, disperso, deslocado, líquido, fragmentado, etc. Mesmo porque, para Latour a modernidade é um projeto que nunca chegou a instalar-se completamente (LATOUR, 1994). Trata-se apenas de reconhecer que os "os sujeitos não são mais autóctones do que as interações face-a-face" e que "quanto mais intensa for a chuva de ofertas de subjetividades, mais interioridade o sujeito adquire" (Latour, 2005, p. 208). Em outras palavras, trata-se de entender aquilo que modernos e pós-modernos chamam de ator social ou sujeito como um ator-rede.

Essa é, sem dúvida, um formulação que reembaralha a sociologia e a psicologia de uma vez por todas. Nesse sentido, tal como o faz com a idéia de "letramento situado", a TAR reabre a discussão em torno da chamada "virada social" nos estudos do letramento (GEE, 2000), não no sentido de contestá-la em favor dos modelos cognitivos e psicolinguísticos que a precederam, mas no sentido de reverter "práticas de purificação" que nos levaram a estudar o letramento inicialmente como fenômeno psicológico e depois como fenômeno sociológico (cultural/ideológico). Nunca houve, do ponto de vista da TAR, um letramento psicológico e letramentos socioculturais. O que houve, e há, são traços, deixados pelos subjetificadores/individualizadores, que, de tão tênues, nos pareciam ser desprezíveis. Não tínhamos como transformar esses traços em inscrições ${ }^{11}$, de modo que só podíamos explicar a maneira como sujeitos/indivíduos letrados agiam recorrendo a alguma força abstrata "lá dentro" ou "lá fora". 
Mesmo nossas mais recônditas idiossincrasias, argumenta Latour, podem ser rastreadas até certos lugares, pessoas, tempos e eventos dos quais simplesmente não mais nos lembramos. Mas o fato é que, do ponto de vista da TAR, nada há em nossa "interioridade" que não nos tenha sido dado. "Como você saberia a que grupo pertence sem baixar [no sentido de fazer download] incessantemente os mesmos clichês culturais com que todos os outros o bombardeiam?”, pergunta Latour (LATOUR, 2005, p. 208) ${ }^{12}$.

Se há um efeito das novas tecnologias sobre o letramento que pouco temos explorado, em contraposição aos muitos que já temos estudado, focalizando as diferenças de "suportes", por exemplo, é justamente o de que os novos letramentos tornaram esses templates e plug-ins imensamente mais fáceis de rastrear. Antes, para entender como um corpo se tornava um alguém (ou vice-versa), podíamos seguir apenas uns poucos veículos, coisas como carteiras de identidade, diplomas, radiografias, etc. Para localizar o gap entre o leitor/escritor genérico e a pessoa que lia/escrevia, tínhamos que recorrer a expedientes como protocolos responsivos, observação participante, diários dialogados, etc. Não é que esses rastros, tanto os encontrados quanto os produzidos artificialmente, tenham perdido sua utilidade. É que a quantidade de rastros deixados pelos atores e o alcance dos instrumentos capazes de produzir inscrições aumentou consideravelmente. As grandes centrais de cálculo, que são, muitas vezes, também grandes centrais de negócios ${ }^{13}$, não param de despejar esses templates e plug ins sobre os letrados digitais em toda parte. Eles, por sua vez, não param de produzir e fazer circular "conteúdos" que são remetidos de volta às centrais na forma de móveis imutáveis, i.e. "realidades que circulam", livres de "contextos" de volta para as centrais de cálculo, de modo que ela possa "contextualizar-se", ou contextualizar aquilo que produz (LATOUR, 2000) ${ }^{14}$.

Enquanto muitos de nós celebramos a conquista de "espaços participativos ampliados", tais como aqueles que os especialistas têm chamado de Web 2.0, muitos outros lamentam o hiperindividualismo que essas circulações de "conteúdos e laços" pessoais fomentam (DEUZE, 2003). Outros, ainda, voltam seus olhares críticos para a denúncia das novas formas de exploração do usuário enquanto trabalhador não remunerado (PETERSEN, 2008). Minha proposta de pesquisa não compartilha nenhum desses objetivos especificamente, embora possa tornar-se uma aliada para alguns deles. Trata-se, simplesmente, de tentar entender letramento (digital) como rede, no sentido da TAR.

Empírica e metodologicamente, compreender letramento como rede pode ser uma tarefa mais ou menos complicada. Tudo depende, por um lado, de quantos e quais atores, mediadores, intermediários, templates e plug ins satisfazem a ambição do pesquisador. De outro, da capacidade do pesquisador, e de seus patrocinadores, de se aterem ao seguinte princípio metodológico da TAR: "devemos permanecer tão indecisos quanto os vários atores que seguimos; sempre que se constrói um divisor entre interior e exterior, devemos estudar os dois lados simultaneamente e fazer uma lista (não importa se longa e heterogênea) daqueles que realmente trabalham" (LATOUR, 2000, p. 421-422).

Não vou detalhar as complicações do primeiro tipo aqui, embora elas sejam importantes, mas, caminhando para o fim de minha reflexão, opto por aproveitar o espaço que me resta para destrinchar um conceito que me parece útil para que cumpramos a demanda de "estudar os dois lados simultaneamente". Trata-se do que os sociólogos da Ciência e Tecnologia Suzan Leigh Star e James Griesemer chamaram de objetos fronteiriços 
(boundary objetcs), em seu trabalho seminal sobre os primeiros anos de funcionamento do Museum of Vertebrate Zoology, na Universidade da Califórnia (STAR; GRIESEMER, 1989).

De maneira sintética, um objeto fronteiriço é um dispositivo (material ou não) que permite que "global" e "local" cooperem entre si a despeito de não compartilharem uma visão consensual e unificada sobre o que, afinal, está sendo feito. Trata-se, em resumo, de uma forma de estabilizar uma translação, no sentido da TAR, compatibilizando heterogeneidade e cooperação por modos outros que não "a imposição imperialista, a coerção, o silenciamento e a fragmentação” (STAR; GRIESEMER, 1989, p. 413).

No clássico estudo de Star e Griesemer sobre o Museu de Zoologia de Berkley, alguns exemplos desses objetos são a estandardização dos métodos, os formulários de relato da coleta de animais e as convenções de rotulação dos espécimes preservados ${ }^{15}$. Explicam os autores que os standards de coleta e rotulagem estabelecidos pelo diretor do museu, e seu pesquisador principal, o biólogo evolucionista Joseph Grinnel, "traduziam as preocupações de seus aliados [amadores que coletavam os animais e os remetiam ao museu] de tal maneira que seu prazer não era prejudicado - atividades básicas como ir acampar, acrescentar itens à coleção pessoal mantida por hobby e preservar a Califórnia permaneceram virtualmente intocadas" (STAR; GRIESEMER, 1989, p. 407).

Eis então o que podemos entender, nos termos da TAR, como uma relação entre local e global, vistos não como utopias ou compartimentos estanques, mas como empreendimentos simultâneos (ou dois lados que trabalham). As interações locais, entre amadores e animais, são pré-formatadas à distância pelo cientista, por meio de objetos fronteiriços (formulários, rótulos, mapas com coordenadas geográficas, etc). Tais atores, por sua vez, dispõem desses documentos e procedimentos como subjetificadores: por meio deles, não são meros veranistas ou andarilhos, mas sim voluntários, coletores de espécimes, amantes da natureza, cidadãos da Califórnia, etc.

O empreendimento capitaneado por Grinnel é financiado pela milionária norte-americana Annie Montague Alexander, uma amante da Zoologia e História Natural, cuja satisfação pessoal e status social obtidos por meio do mecenato das artes e das ciências naquela sociedade são notórios. Não a teoria de evolucionismo que Grinnel tentava desenvolver, mas a ideia de conservacionismo, que emerge como valor na sociedade californiana do início do século XX, é o que move Alexander. Mas o fato é que, assim como aos fazendeiros, coletores amadores e caçadores que doavam os animais coletados, Grinnel oferece a Alexander subjetificadores em troca de um certo tipo de trabalho que ela pode interpretar como conservacionismo.

Todos esses lados que trabalham, como bem mostram Star e Griesemer, são levados a agir pelos outros lados, mas nenhum deles está submetido à interpretação particular dessa ação feita pelos demais, tampouco precisa alinhar-se com essa interpretação para fazer o que deseja. Quer sejam humanos ou não-humanos, centrais ou periféricos, locais ou globais, todos esses atores se fortalecem, de alguma forma, nos vínculos que os enredam. Quanto mais articulados se tornam, mais eles existem, e mais podem agir.

Proponho agora uma analogia de modo a ilustrar a utilidade do conceito de objeto fronteiriço, no sentido em que é utilizado pela TAR, para a pesquisa em letramento digital. Um jovem engenheiro, chamado Orkut Buyukkokten publica com dois colegas um paper que tem o sugestivo nome de "A social netowork caught in the web" (LADA et al, 2003), com o qual me deparo na 
WWW, enquanto preparo a bibliografia de um curso de pós-graduação. Trata-se do mesmo engenheiro que dá nome ao notório site de redes sociais Orkut, pertencente à companhia Google, da qual Buyukkokten é hoje empregado, um site para o qual meus alunos de graduação, seus usuários, são frequentemente levados a me convidar, quando o software do programa de correio eletrônico Gmail, pertencente à mesma companhia, produz inscrições a partir dos "laços" possíveis que identifica quando rastreia os emails que eu e meus alunos trocamos.

O paper com qual me deparei traz resultados de uma série de análises realizadas pelos autores a partir de dados coletados via formulários de cadastro em um site semelhante ao Orkut, criado pelo próprio engenheiro e seus colegas quando ainda estudantes na Universidade. A figura 1 é uma das inscrições contidas no paper. Ela exemplifica o tipo de empreendimento "global" em que Buyukkokten e seus colegas estão engajados ${ }^{16}$ :

Table 1: Personality traits and positive correlations to majors.

\begin{tabular}{|c|c|c|}
\hline & $\begin{array}{c}\text { personality (percent } \\
\text { of total) }\end{array}$ & major \\
\hline \multirow{6}{*}{$\begin{array}{l}\text { free } \\
\text { time }\end{array}$} & learning $(17 \%)$ & $\begin{array}{l}\text { Physics }(46 \%) \text {, Philosophy }(37 \%) \text {, Math }(31 \%) \text {, Electrical } \\
\text { Engineering }(26 \%) \text {, and Computer Science }(24 \%)\end{array}$ \\
\hline & reading $(26 \%)$ & English $(55 \%)$ \\
\hline & $\begin{array}{l}\text { staying at home } \\
(8 \%)\end{array}$ & History $(24 \%)$ \\
\hline & $\begin{array}{l}\text { doing anything } \\
\text { exciting }(52 \%)\end{array}$ & undecided $/$ undeclared $(62 \%)$ \\
\hline & $\begin{array}{l}\text { fulfilling commitments } \\
(16 \%)\end{array}$ & Psychology $(27 \%)$ \\
\hline & watching TV $(17 \%)$ & International Relations ( $26 \%$ ) \\
\hline \multirow{10}{*}{ you } & intelligent $(32 \%)$ & Philosophy $(59 \%)$ and Computer Science $(42 \%)$ \\
\hline & successful $(4 \%)$ & Computer Science $(7 \%)$ \\
\hline & $\begin{array}{l}\text { socially adaptable } \\
(14 \%)\end{array}$ & Science, Technology, and Society $(46 \%)$ \\
\hline & attractive $(16 \%)$ & Political Science $(29 \%)$ and International Relations $(25 \%)$ \\
\hline & lovable $(12 \%)$ & Political Science $(24 \%)$ \\
\hline & kind $(25 \%)$ & Public Policy $(45 \%)$ \\
\hline & weird $(12 \%)$ & Physics $(34 \%)$, Math $(28 \%)$, and Electrical Engineering $(18 \%)$ \\
\hline & fun $(26 \%)$ & Human Biology $(38 \%)$ \\
\hline & creative $(22 \%)$ & Product Design $(62 \%)$ and English $(42 \%)$ \\
\hline & $\operatorname{sexy}(8 \%)$ & English (18\%) \\
\hline
\end{tabular}

Figura 1 - Fragmento de análise da rede social online Club Nexus realizada por Lada e colegas

No excerto 1 , os autores explicam os resultados de sua análise sobre a correlação entre certos termos, indicadores de certas qualidades ("trusty", "nice", "cool", e "sexy"), utilizados pelos usuários do site para descrever outros usuários com os quais mantém algum tipo de laço social ( chamados "buddies"), e a quantidade de buddies arregimentada por cada usuário.

\section{Excerto 1}

We found mild or negligible correlation between a person's average ranking in each category and the number of buddies that they have. This negates the hypothesis that people perceived as cool or nice have more friends 
Note-se que esse simples excerto nos leva de volta ao que, no início dessa reflexão, está referido por "concepção performativa do social". O que Orkut e seus colegas fazem com essa inscrição é nada menos do tentar definir o é o social “ostensivamente", isto é, em termos de laços, atributos e correlações entre laços e atributos. Parece haver, para eles, um social "lá fora" que pode ser capturado e descrito matematicamente, de modo a gerar previsões, exatamente como havia, para Grinnel, um "evolucionismo" a ser explicado em termos de atributos morfológicos dos espécimes e suas localizações geográficas. A pergunta que se coloca, a partir disso é: como pensar em letramento digital ou inclusão digital, de forma útil aos que trabalham do lado de cá de um objeto fronteiriço como o Orkut, sem entender que é isso que se passa do lado de lá?

Os usuários do site de relacionamentos, assim como os caçadores, coletores amadores e fazendeiros interessados por Grinnel, fornecem os dados de que Orkut e colegas necessitam, ainda que nada do que façam tenha, para eles, localmente, o mesmo significado que tem para os autores do paper. Do lado de lá do objeto fronteiriço, esses mesmos atributos, formulados como adjetivos digitados em um formulário de perfil, e as ligações entre os usuários, que se conectam mutuamente por meio do site, são subjetificadores ou personificadores. Já não são "usuários" genéricos, mas buddies, internautas, orkuteiros. Suas interações locais, pré-formatadas por meio de templates que engenheiros como Buyukkokten lhes fornecem para que possam entender que ali existe um lugar onde é possível "socializar-se", produzem inscrições circulam de volta, como móveis imutáveis, para a central de cálculo. O gap entre o que esses sujeitos são enquanto usuários genéricos (como aparecem no paper) e enquanto pessoas amigas entre si é preenchido por subjetificadores e individualizadores que podem ser rastreados (scaps, links, fotos, declarações, avatares, etc), possivelmente alcançáveis por alguém que, como eu, se interesse em segui-los a partir de outros laboratórios.

Obviamente, o patronato de empreendimentos como o site de relacionamentos Orkut não é do mesmo tipo que o relatado no caso do Museu. Mas, também nesse caso, não deixa de ser identificável. O vínculo a ser seguido aqui é o nome da companhia que financia a construção e o funcionamento do site de relacionamentos, a mega empresa de tecnologia Google. "Organizar a informação mundial e torná-la universalmente acessível e útil” é o que a companhia declara ser sua missão (GOOGLE, s.d.). Para sustentá-la, a empresa obtém recursos financeiros vendendo "links patrocinados", que aparecem ao lado dos resultados "gratuitos" das buscas feitas por internautas do mundo inteiro no buscador da Google.

"Tornar a informação universalmente acessível e útil" é algo que a empresa não pode fazer sozinha, porque uma mesma palavra "sem contexto" que designa algo útil para cada um de seus usuários, pode designar algo inútil para cada um dos outros os outros. Daí que, para ela, patrocinadora, assim como para Alexander, no caso do Museu, o significado do Orkut seja outro. Os subjetificadores e individualizadores que ali ficam registrados são aliados num empreendimento que poderíamos tranquilamente descrever como sendo o de "contornar a língua". Esses subjetificadores e individualizadores representam capital ou valor para a companhia apenas na medida em que eles vão permitido a ela oferecer aos seus clientes, sejam eles usuários de seus produtos ou anunciantes, respostas mais e mais precisas e relevantes sobre onde encontrar qualquer tipo de coisa ou pessoa. Não 
há nada que a companhia possa chamar de "informação" ou "utilidade" fora dessas circulações. Tampouco há qualquer tipo de competência, affordance ou restrição que possamos totalizar e isolar olhando isoladamente para o lado de cá ou de lá da tela do computador.

Passo agora ao relato de uma interação local, a qual já examinei por meio de outras lentes, que não a TAR, com o fito de descobrir o que daí se tira a partir do que discuti ao longo deste trabalho. Creio que isso sirva como aquilo que, na TAR, se chama de prova de força, para convencer aqueles que convido a pesquisarem comigo de que esse empreendimento vale a pena.

T. é uma estudante de quatorze anos, frequentadora assídua de um telecentro na periferia de uma cidade industrial próxima a São Paulo ${ }^{17}$, ao qual habitualmente dirige-se logo após o período escolar, e, quando possível, acompanhada de uma prima e algumas colegas da mesma escola. Quando a abordei, estava utilizando o site de relacionamentos Orkut e, ao mesmo tempo, interagindo via MSN com uma amiga sentada à frente de outro computador, no mesmo laboratório. Dado que se trata de um laboratório, supõe-se as interações sejam silenciosas. Mas não há, de fato, silêncio semiótico algum nesse evento. Há apenas certos os atores cuja ação vemos, e outros cuja ação não percebemos.

A aproximação de T. com o telecentro se deu, como no caso de muitos dos jovens que lá conheci, por conta de dois interesses: realizar tarefas escolares (basicamente pesquisas na web e redações no processador de textos) e passar o tempo livre longe dos "perigos da rua", enquanto aguardava seus pais chegarem do trabalho. No dia em que a abordei, T. tinha duas janelas do programa de navegação abertas na tela (além do box de bate-papo do comunicador instantâneo). Em uma delas, via-se um perfil no Orkut. A outra exibia resultados de busca no Google Images, no qual T. acabara de localizar a foto da amiga com quem batia papo no comunicador. Essa amiga estava criando sua conta no Orkut e desejava utilizar tal foto em seu perfil, mas não sabia como recuperá-la. T. sabia que a foto existia no blog de alguém que conhecera, e utilizou o buscador para rastreá-la. Seu próximo passo seria fazer o upload da foto para o perfil da amiga, que lhe fornecera, com esse propósito, seu nome de usuário e senha no Orkut.

Vasculhei, a convite de T., seu perfil no site de relacionamentos. Entre seus scraps, havia, por exemplo: (1) e ai [nome do destinatário].kuanto tempo heimm, (2) Oi, [nome do destinatário], adorei sua visita la em casa, volte sempre, hein?”, (3) aff vc saiiu ou me block? Já as "comunidades" a que estava filiada incluíam, entre outras, (4) estudei no Imaculada, (5) Nasci de novo, (6) Tocava a campainha e corria, (7) Já me jogaram na piscina, (8) Sou canhoto, (9) Adoro minha mãe, (10) Odeio lavar louça, (11) Foda-se quem em odeia, (12) Conta comigo.

Parece-me que podemos chamar seus scraps de localizadores e os títulos das comunidades de que participa de subjetificadores e personalizadores. Por certo, estes terão sido coletados, armazenados e utilizados em cálculos diversos pelos cientistas, engenheiros e especialistas em Marketing que trabalham do outro lado do Orkut, embora eu não consiga imaginar, pensando no tipo de cálculo que encontrei no paper de Orkut e seus colegas, qual seria a utilidade de calcular as chances estatísticas de alguém que "nasceu de novo" vir a "adorar sua mãe" ou "ser jogada na piscina". Em verdade, nem mesmo posso saber, com certeza, se esses subjetificadores e personalizadores são de F., já que ela troca seu nome de usuário e senha com suas amigas. 
O fato é que, cada um desses "lados que trabalham", os pesquisadores (eu e possivelmente muitos dos leitores deste trabalho), os engenheiros, as companhias, os usuários, os acionistas, os que fazem buscas no Google, os computadores, os que patrocinam o telecentro, e tantos outros atores humanos e não-humanos aí enredados é levado, pela relação que travam uns com os outros, a agir, sem que, em princípio, nenhum deles compreenda exatamente o que o outro está fazendo localmente. Entretanto, nenhuma descrição ou suposição sobre o que cada um deles faz seria tão instigante quanto uma explicação sobre o que cada um deles faz o outro faz̧er.

Quando entrevistei o administrador do telecentro, descobri que, para ele, aquele letramento de T. era pura perda de tempo, equivalente a assistir novelas antigas na TV em lugar de estudar ou aprender algo novo com os livros ou com os computadores. Os computadores do telecentro, financiados pelo governo federal, equipados com software livre, e descritos pelo administrador como uma "oportunidade impar" de (re)qualificação profissional para aquelas pessoas, tinham passado de intermediários a mediadores no mesmo momento em que T. passara de estudante carente a orkuteira. T., concluí já à época, havia sido deslocada, ela mesma, da periferia para a fronteira. Mas o que havia ali, só agora consigo ver, não era um ator social conectado a um computador que lhe demandava um letramento para o qual ela desenvolvera internamente uma competência. Era um ator-rede, isto é, algo que não pode ser explicado por uma meta-linguagem que remeta a um social "lá fora" ou a uma competência "lá dentro", mas apenas por "algum tipo de infra-linguagem cujo papel é simplesmente ajudar [o analista] a tornar-se atento à meta-linguagem totalmente desenvolvida dos atores" (LATOUR, 2005, P. 49; itálicos no original). Penso que a TAR pode vir ser essa infra-linguagem, algo a ser demonstrado em futuras provas de força.

\section{Notas}

${ }^{1}$ Trabalho produzido no âmbito do projeto de pesquisa "Letramento, Fronteiras e Cultura Digital", financiado pela FAPESP sob o número de processo 2009/00671-7.

${ }^{2} \mathrm{O}$ argumento latouriano diz que os pré-modernos, justamente por não separarem radicalmente natureza e cultura, colocando-as em campos ontológicos distintos, estancariam a proliferação dos híbridos.

${ }^{3}$ Digo "supostamente" porque em verdade deterministas e neutralistas se encontram ao isolar o técnico do social.

${ }^{4} \mathrm{O}$ conceito de affordance, oriundo da psicologia ambiental (GIBSON, 1979), tem sido explorado, em especial, no que tange as tecnologias das letras, por autores interessados na multissemiose/multimodalidade/ multimidialidade que caracteriza os textos e dispositivos digitais (KRESS, 2005, por exemplo).

${ }^{5}$ Essa ênfase sobre o "local" é sem dúvida impulsionada por trabalhos do assim chamado modelo ideológico do letramento, publicados nas últimas duas décadas do século XX. A revisão da questão dos letramentos situados a partir da TAR é bastante mais recente (BRANDT; CLINTON, 2002).

${ }^{6}$ Entendidos, a partir daqui, tanto em termos de "escala de análise" como em termos "geopolíticos".

${ }^{7}$ Os três princípios não destacados aqui são os seguintes: "nenhuma interação é sincrônica" (i.e. os atores não têm as mesmas idades nem o mesmo ritmo), "interações não são sinópitcas" (i.e. apenas alguns poucos do total de atores envolvidos em uma certa ação são visíveis ao mesmo tempo) e "interações não são isobáricas" (i.e. alguns dos participantes demandam ser ouvidos/levados em conta enquanto outros permanecem "submersos", em hábitos corporificados, por exemplo).

${ }^{8}$ Uma palestra proferida em um auditório para estudantes universitários. 
${ }^{9}$ Estou me referindo aqui ao que, na TAR, se chama de dispontualização (LAW, 1992), isto é, ao momento em que, porque uma máquina, idéia, fato, ou pessoa pára de fazer seu papel discretamente e sem desvios, ele/ela imediatamente se abre para o analista como uma rede (e não um ponto na rede). Por exemplo, um computador que falha, por exemplo, quando o estamos usando para baixar um arquivo da Internet, deixa de ser "um computador" e, imediatamente, transforma-se numa rede que concatena placas, drivers, plug-ins, protocolos de rede, fontes de alimentação, regras impostas pelo administrador da rede, vírus de computador, mensalidades pagas ao provedor de acesso, etc. Outra maneira de dizer isso é que a dispontualização é um mecanismo pelo qual um intermediário se transforma em um mediador diante de nossos olhos.

${ }^{10}$ É dessa competência, ou da falta dela, sem dúvida, que nos falam os que se referem ao "analfabetismo funcional", por exemplo. É também ela, me parece, que se tenta mensurar com aquilo que os designers de interface e engenheiros de software chamam de "usabilidade".

${ }^{11}$ Formas duráveis de registro (de qualquer tipo) que permitem ao cientista fazer de um mundo complexo e desordenado um conjunto de fatos "legíveis" (LATOUR, 2000).

${ }^{12}$ Latour reconhece, em nota de rodapé, na mesma página, o valor do insight vygotskyiano, tão familiar aos que estudam letramento, nesse sentido. Entendemos que, da mesma forma, haverá de reconhecer os insights bakhtinianos a que nos remetem a termos como dialogismo, intertextualidade, polifonia, entre outros. Isso é importante, penso, porque conecta a TAR a aliados de que já dispomos nos estudos sobre o letramento e reabre um interessante campo de negociações sobre o conceito de "social" no campo aplicado dos estudos da linguagem.

${ }^{13}$ Refiro-me a todos os tipos de laboratórios, ou lugares onde se trabalha, o que inclui de escritórios de marketing a universidades e a companhias de alta tecnologia que oferecem serviços (de busca e outros) na Internet, por exemplo.

${ }^{14}$ Refiro-me aqui, por exemplo, ao projeto de uma "web semântica", que não pode prescindir dos conteúdos e relações entre usuários disponibilizados por eles mesmos em lugares como sites de redes sociais.

${ }^{15}$ Atenho-me, aqui aos objetos fronteiriços figurativizados como textos, na pesquisa em questão, de modo a facilitar a conexão do conceito com minha argumentação sobre letramento.

${ }^{16}$ Nesse caso, estudantes da mesma universidade norte-americana em que estudavam/trabalhavam os autores.

${ }^{17}$ Dados que utilizo aqui apenas para ilustrar os conceitos por meio de um caso documentado em pesquisa anterior (BUZATO, 2007).

\section{Bibliográfia}

BUZATO, M. E. K. Entre a Fronteira e a Periferia: Linguagem e Letramento na Inclusão Digital. 2007. Tese (Doutorado em Lingüística Aplicada) - Instituto de Estudos da Linguagem, Universidade Estadual de Campinas, Campinas, 2007.

.Letramento e inclusão: do estado-nação à era das TIC. DELTA - Documentação de Estudos em

Lingüistica Teórica e Aplicada, v. 25, p. 1-38, 2009.

CHARTIER, Roger. A aventura do livro: do leitor ao navegador; conversações com Jean Lebrun. São Paulo: UNESP/IMESP, 1999.

CLARKE, J. Using actor-network theories for the study of literacy events and practices in global and local settings. International Literacy Conference, Cape Town. 2001. Disponível em <http://www.ched. uct.ac.za/literacy/Papers/ClarkePaper1.html > Acesso em 10 mai 2007.

DEUZE, Mark. Participation, Remediation, Bricolage: Considering Principal Components of a Digital Culture. The Information Society, Bloomington, v. 2, n. 22, p.63-75, 2003.

GEE, James Paul. The New Literacy Studies and the Social Turn. In: David Barton, Mary Hamilton, Roz Ivanic. Eds.. Situated Literacies: Reading and Writing in Context. London: Routledge, 2000.

GIBSON, J.J. The ecological approach to visual perception. New Jersey: L. Erlbaum, 1979. 
GOODY, Jack. The Logic of Writing and the Organization of Society. Cambridge: CUP, 1986.

GOODY, Jack.; WATT, Ian. The consequences of literacy. Comparative Studies in Society and History, Cambridge, v. 5 , n. 3, p. 304-45, 1963.

GOOGLE. Welcome to Google Enterprise. Disponível em <http://www.google.com/enterprise/ whygoogle.html> acesso em 12 Dez, 2009

HAMILTON, M. Priviledged literacies: policy, institutional process and the life of IALS. Language and Education, v.15, p. 178-196, 2001.

HEATH, Shirley Brice. Ways with words. Cambridge: Cambridge University Press, 1983.

IADEMA, R. A. M. Multimodality, resemiotization: extending the analysis of discourse as multi-semiotic practice. Visual Communication, v. 2, n.1,2003, p. 29-57.

KRESS, G. Gains and losses: New forms of texts, knowledge, and learning. Computers and Composition, v.22, n.1, p.5-22, 2005.

LADA, Adamic; ORKUT, Buyukkokten; Adar, EYTAN. A social network caught on the web. First Monday, v. 8, n. 6, 2003.

LATOUR, Bruno. Jamais fomos modernos: ensaio de antropologia simétrica. Rio de Jan.: Editora 34, 1994. .Ciência em Ação: como seguir cientistas e engenheiros sociedade afora.São Paulo: Editora Unesp, 2000. .Reassembling the Social: an introduction to actor-network-theory. NewYork: OUP, 2005.

LAW, John. Notes on the Theory of the Actor-Network: Ordering, Strategy, and Heterogeneity. Systems Practice, v.5, n. 4, p. 379-393,1992.

LEANDER, K; LOVVORN, J. F. Literacy Networks: Following the Circulation of Texts, Bodies, and Objects in the Schooling and Online Gaming of One Youth. Cognition and Instruction, n. 24, v. 3, p. 291-340, 2006.

MAINGENEAU, Domminique. O Contexto da Obra Literária. S. Paulo: Martins Fontes, 1995.

OLSON, David. From utterance to text: The bias of language in speech and writing. Harvard Educational Review, Cambridge, MA, v.47, n.3, p. 257-281, 1977.

PETERSEN, Søren Mørk. Loser Generated Content: From Participation to Exploitation. First Monday, v. 13, n. 3, 2008.

SCRIBNER, S.; COLE, M. The psychology of literacy. Cambridge, MA: Harvard University Press, 1981.

STREET, Brian V. Literacy in Theory and Practice. Cambridge: Cambridge University Press, 1982.

STRUM, Shirkey; LATOUR, Bruno. The meanings of social: from Baboons to Humans In: Social Science Information, v. 26, p. 783-802, 1987.

VIEIRA, Miguel Said. Bens comuns intelectuais: dos que temos aos que queremos. III Encontro Nacional Sobre Hipertexto, Belo Horizonte, MG - 29 a 31 de outubro de 2009, Anais.

WARSCHAUER, M. J. Technology and Social Inclusion: rethinking the Digital Divide. MIT Press, 2003. 